\title{
On Conformable Double Sumudu Transform
}

\author{
suliman alfaqeih ${ }^{1}$, Gizel bakicierler ${ }^{2}$, and Emine Misirli ${ }^{2}$ \\ ${ }^{1}$ Ege Universitesi \\ ${ }^{2}$ Ege University
}

May 6, 2020

\begin{abstract}
In the current work, we have introduced a new deformation and generalization of the Sumudu transform called the Conformable Double Sumudu Transform (CDST), which can be applied to solve conformable fractional partial differential equations (CFPDEs). Further, we proposed some fundamental properties of the (CDST). To show the efficiency, applicability, high accuracy, and simplicity of the proposed transform, we apply this new transform to solve a wide class of linear fractional partial differential equations in the sense of Conformable fractional derivative (CFD).
\end{abstract}

\section{Hosted file}

29-4.pdf available at https://authorea.com/users/317569/articles/447628-on-conformabledouble-sumudu-transform 